\title{
Thermobaric Sintering of Mechanocomposites of the
}

\section{System Fe-Ga}

\author{
Tatyana Grigorieva $^{1 *}$, Svetlana Kovaleva ${ }^{2}$, Vladimir Senyut ${ }^{2}$, Petr Vityaz ${ }^{2}$ and Nikolay Lyakhov ${ }^{1}$ \\ 1. Institute of Solid State Chemistry and Mechanochemistry of SB of RAS, Novosibirsk, 630128, Russia \\ 2. The Joint Institute of Mechanical Engineering of the NAS of Belarus, Minsk, 220072, Belarus
}

\begin{abstract}
Alloys of the system Fe-Ga obtained by sintering under high pressure and temperature from mechanocomposites formed during MA (Mechanical activation) in different modes were investigated. Structural studies were carried out by means of X-ray diffraction, optical and scanning electron microscopy. It was demonstrated that the sintered materials inherit the phase composition of mechanocomposites. It was established that sintering at high pressure and temperature leads to further decrease in the size of $\alpha$-Fe crystallites. The presence of the low-melting component in mechanochemically synthesized precursor after MA for a short time promotes the formation of microstructure according to the liquid-phase sintering mechanism. Sintering of mechanocomposites formed from the solid solution based on $\alpha$-Fe proceeds according to the solid-phase mechanism with homogeneous distribution of components, and microhardness of these materials increases by a factor of 2 .
\end{abstract}

Key words: Mechanocomposites, mechanical activation, termobaric sintering, microstructure.

\section{Introduction}

It is known that the alloys of the Fe-Ga system possess magnetostrictive properties [1, 2], which allows their use in magnetoelectric structures of sensors, magnetic field converters and vibrogenerators. The structural features of these alloys, its properties and the methods for obtaining materials based on these alloys are under active investigation [3, 4].

Mechanochemical method is one of relatively easy and efficient means of making mechanocomposites and obtaining intermetallic compounds [5].

The formation of functional materials based on mechanically activated powders with the conservation of their structural state is an essential technological objective [6]. The major problems arising from compacting and sintering of nanostructured powder are rapid grain growth and high porosity of material. In this connection, sintering at high pressure is the most promising method to obtain voluminous

*Corresponding author: Tatyana Grigorieva, Dr., research fields: mechanochemistry, mechanochemical interaction between solid and liquid metals. nanostructured composites and intermetallic compounds. High-pressure sintering allows one to decrease the temperature of alloy formation, slow down recrystallization processes and conserve the nanostructure of thus obtained material.

The goal of the present work was to study the effect of the regimes of mechanical activation of $\mathrm{Fe}-\mathrm{Ga}$ mixture on the structure of sintered alloys obtained under the conditions of high pressure and temperature.

\section{Experimental Setup}

Precursors for sintering were mechanocomposites $\mathrm{Fe} / 20 \% \mathrm{Ga}$, obtained using carbonyl-grade iron and gallium in a high-energy ball planetary mill AGO-2 with water cooling in the atmosphere of argon.

Sintering was carried out at high pressure and temperature in a pressing set-up DO-138 B with the strain of $630 \mathrm{t}$ in the high-pressure anvil-with-well apparatus at a pressure of $2.5 \mathrm{GPa}$ and a temperature of $700{ }^{\circ} \mathrm{C}$. Isothermal exposure was $15 \mathrm{~s}$. The diameter of cylindrical samples after sintering was $5 \mathrm{~mm}$, their height was $3 \mathrm{~mm}$.

Diffraction studies of the alloys were carried out 
with a D8 Advance Diffractometer (Germany) with the characteristic radiation of the copper anode of $\mathrm{X}$-ray tube $\mathrm{Cu} K_{\alpha 1}(\lambda=1.5406 \AA)$ in Bragg-Brentano configuration $\theta-2 \theta$. Scanning was carried out at room temperature over points with a step of $0.05^{\circ}$ and the time of X-ray quanta integration in a point equal to $3 \mathrm{~s}$. Calculation and refinement of profile and structural parameters were carried out using the least squares procedure with the complete profile analysis of diffraction patterns with the help of TOPAS (Total pattern analysis solutions) software using Pawley's iteration procedure. Studies of microstructural characteristics (crystallite size $<\mathrm{L}>$ and microstrains) were carried out using the double Voight methodology, in which diffraction profiles on crystallite size and on micro distortions are described in the generalized form by Voight's functions. To separate the contributions into peak broadening from L, Lorentz function was used, and from microstrain $\varepsilon$ - Gauss function was used.

The structure of the obtained samples was studied using the Micro 200 optical microscope and high-resolution scanning electron microscope
MIRAITESCAN with attachment for XRSA (X-ray spectral microanalysis). The diameter of the electron probe was $5.2 \mathrm{~nm}$.

Microhardness of sintered samples was measured with a PMT-3 microhardness measuring device with a load of $\mathrm{P}=1.96 \mathrm{H}$.

\section{Experimental Results}

The Fe-Ga system is chemically interacting system and, according to Miedema [7], it exhibits negative enthalpy of mixing for all concentrations of components.

According to the equilibrium diagram [8] (Fig. 1), four intermetallic compounds exist in the system Fe-Ga. The solubility of iron in gallium is insignificant but the solubility of gallium in iron reaches 35.1 at. $\%$ at the high temperature $\sim 1037{ }^{\circ} \mathrm{C}$. Compounds $\mathrm{Fe}_{3} \mathrm{Ga}_{4}$ and $\mathrm{FeGa}_{3}$ are formed at temperatures of $906{ }^{\circ} \mathrm{C}$ and $824{ }^{\circ} \mathrm{C}$, respectively. Compound $\mathrm{Fe}_{6} \mathrm{Ga}_{5}$ is formed at a temperature of $800{ }^{\circ} \mathrm{C}$ from the solid solution of $\mathrm{Ga}$ in $\alpha-\mathrm{Fe}$ and compound $\mathrm{Fe}_{3} \mathrm{Ga}_{4}$, and undergoes polymorphous transformation at $778{ }^{\circ} \mathrm{C}$.

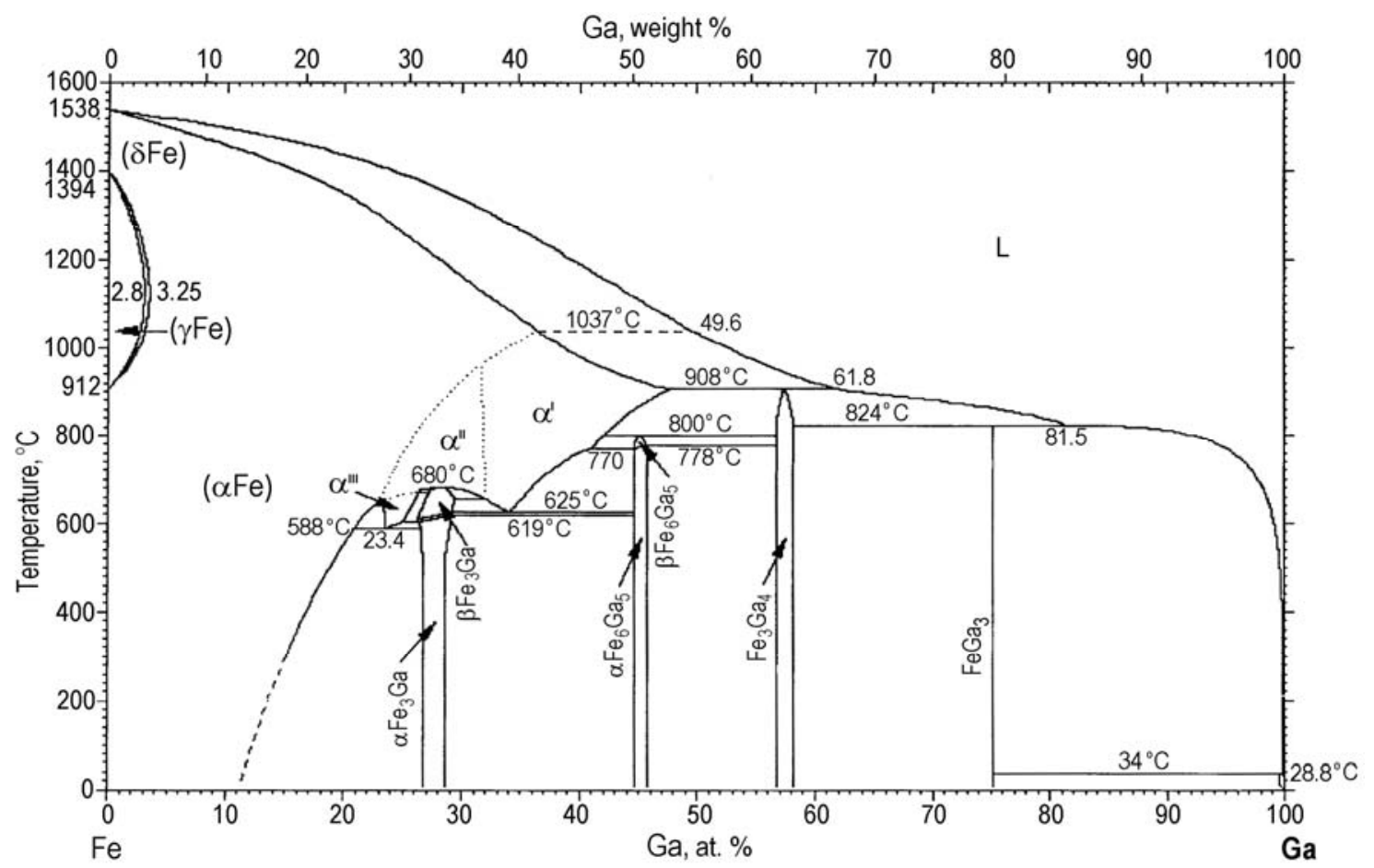

Fig. 1 Equilibrium diagram of the Fe-Ga system. 
Previous studies of the evolution of structural phase transitions during mechanical activation in the system $\mathrm{Fe}-20 \%$ Ga revealed the formation of composite structure of powders at all stages of MA [9]. The sequence of changes in the phase composition of powders during activation is described by reactions:

$$
\begin{gathered}
\mathrm{Fe}+\mathrm{Ga} \rightarrow \mathrm{Fe}+\mathrm{FeGa}_{3} \rightarrow \mathrm{Fe}+\mathrm{Fe}(\mathrm{Ga})_{\text {disordered }} \rightarrow \\
\mathrm{Fe}+\mathrm{Fe}(\mathrm{Ga})_{\text {disordered }}+\mathrm{Fe}_{3} \mathrm{Ga}\left(D 0_{3} \text { and } \mathrm{L}_{2}\right)
\end{gathered}
$$

Powder particles after MA mainly have scaly and fractures shapes; the average size of agglomerates does not change during activation and is equal to 1.5-2 $\mu \mathrm{m}$. An increase in the time of mechanical treatment to $12 \mathrm{~min}$ leads to the formation of intermetallic compound with the largest content of low-melting element without substantial changes in the structural state of the $\alpha-\mathrm{Fe}$ phase. The start of the formation of disordered solid solution $\mathrm{Fe}-(\mathrm{Ga})$ is detected only after MA for $60 \mathrm{~min}$. By this time, intermetallic compound $\mathrm{FeGa}_{3}$ disappears, and the size of coherent scattering area of $\alpha$-Fe phase decreases from 35 to $8 \mathrm{~nm}$. After MA for $120 \mathrm{~min}$, the start of local ordering of the solid solution of gallium in iron according to the type $\mathrm{Fe}_{3} \mathrm{Ga}\left(\mathrm{DO}_{3}\right.$ and $\left.\mathrm{L1}_{2}\right)$ is observed; after MA for 150 min a composite structure of the disordered solid solution with locally ordered $\mathrm{Fe}_{3} \mathrm{Ga}$ regions according to the $D 0_{3}$ and $L 1_{2}$ type is formed.

Powdered mechanocomposites after MA for 2, 12 and $150 \mathrm{~min}$ were used for sintering.

The diffraction patterns of alloys sintered under the conditions of high pressure and temperature are presented in Fig. 2 in comparison with the initial powders after MA for different times.

After sintering mechanically activated Fe-20\% Ga powders at high pressure and temperature, a decrease in the size $<\mathrm{L}>$ of $\alpha$-Fe crystallites is observed in alloys in comparison with mechanocomposites, which may be connected with the development of intense plastic deformations under pressure and fragmentation of iron grains. Crystallite size does not decrease below $5 \mathrm{~nm}$.
For pure $\alpha-F e$, the minimal size of crystallites controlled by only plastic deformation is $\langle\mathrm{L}\rangle_{\min } \sim 9 \mathrm{~nm}$. A decrease in crystallite size to $5 \mathrm{~nm}$ may be due to the formation of solid solution. Sintering process is accompanied by internal strain relaxation.

Grain structure is formed during sintering $\mathrm{Fe} / 20 \%$ mass Ga mechanocomposites. In the alloy based on powders activated mechanically for $2 \mathrm{~min}$, the grains and pores have rounded shape, which is characteristic of liquid-phase sintering, with the dissolution of the solid phase in liquid. The average size of iron grains was 3-8 $\mu \mathrm{m}$. Dispersed particles of the intermetallic compound $\mathrm{FeGa}_{3} \sim 500 \mathrm{~nm}$ in size are situated along the boundaries of coarse iron grains. It may be assumed that after MA for 2 min gallium or $\mathrm{Ga}(\mathrm{Fe})$ is present in disordered iron layers; it is not detected in $\mathrm{X}$-ray diffraction patterns but promotes the appearance of the melt under the conditions of high temperature and pressure.

Grain size in the alloy obtained by sintering the powder after MA for $12 \mathrm{~min}$ decreases to 1-6 $\mu \mathrm{m}$. $\mathrm{X}$-ray phase (Fig. 2b) and X-ray spectral analysis (Fig. 3a) showed a substantial decrease in the amount of $\mathrm{FeGa}_{3}$ phase and the formation of additional intermediate intermetallic compounds $\mathrm{Fe}_{3} \mathrm{Ga}_{4}$ and $\mathrm{Fe}_{6} \mathrm{Ga}_{5}$. According to the data of X-ray spectral analysis, the formation of the surface diffusion layer of gallium in iron is observed on the particles of $\alpha$-iron. The phase composition of sintered material based on precursors activated mechanically for $12 \mathrm{~min}$ is: $\alpha-\mathrm{Fe}+\mathrm{FeGa}_{3}+\mathrm{Fe}_{3} \mathrm{Ga}_{4}+\mathrm{Fe}_{6} \mathrm{Ga}_{5}$. With an increase in MA time to $12 \mathrm{~min}$, the surface porosity (which is equal to the ratio of pore area in the section to the total area of the section) decreases from $17 \%$ (for powders sintered after MA for $2 \mathrm{~min}$ ) to $3 \%$. Porosity is mainly intergranular in mechanocomposites sintered from the powders after MA both for $2 \mathrm{~min}$ and for $12 \mathrm{~min}$.

High-pressure and high-temperature sintering of powders after MA for 150 min proceeds according to the type of solid phase reactions. In this case, the structure with different grain sizes is formed; grain size 

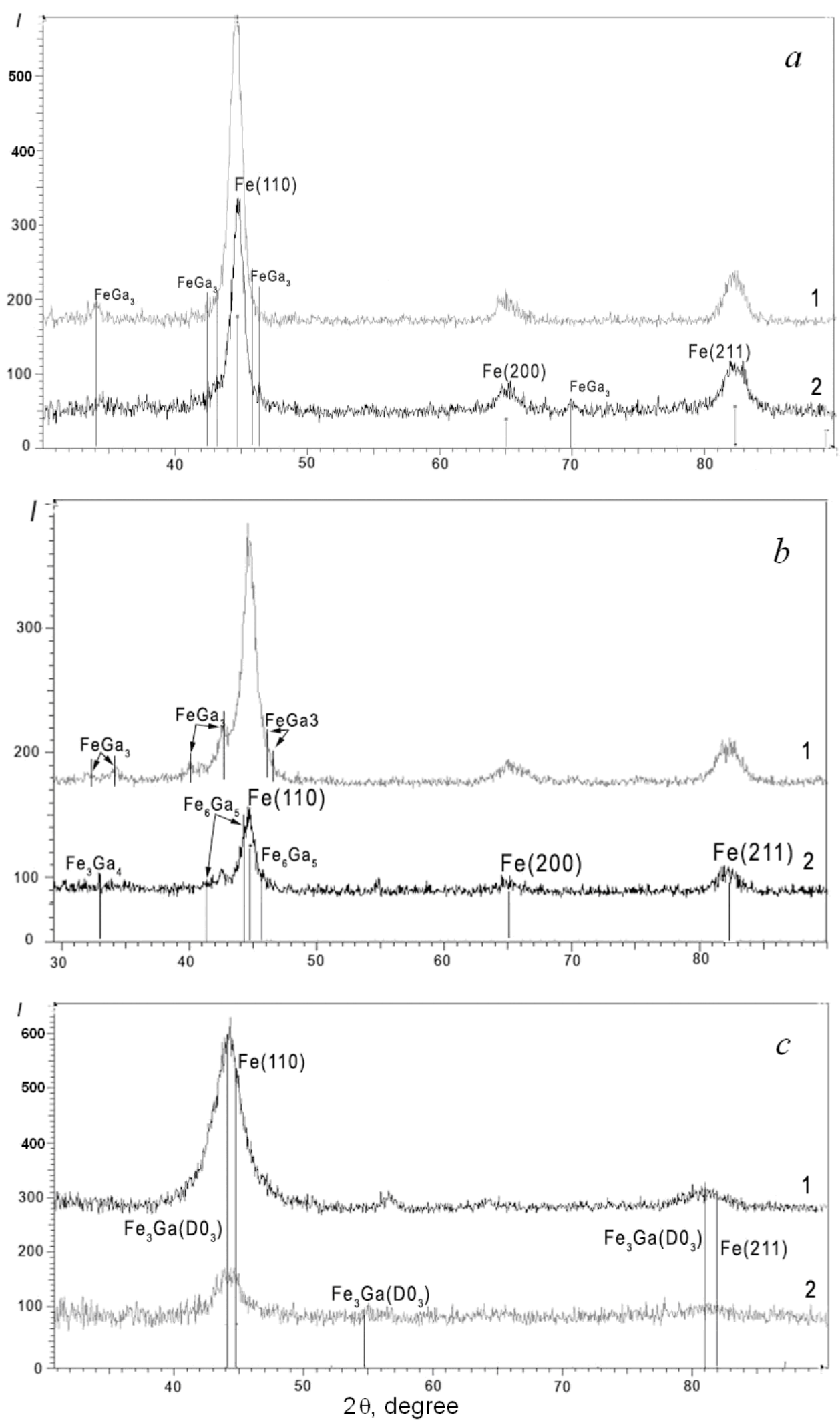

Fig. 2 Diffraction patterns of the sintering material (2) based on MA-precursor Fe-20 \% Ga (1) after activation for: (a) 2 min, (b) $12 \mathrm{~min}$ and (c)150 min. 

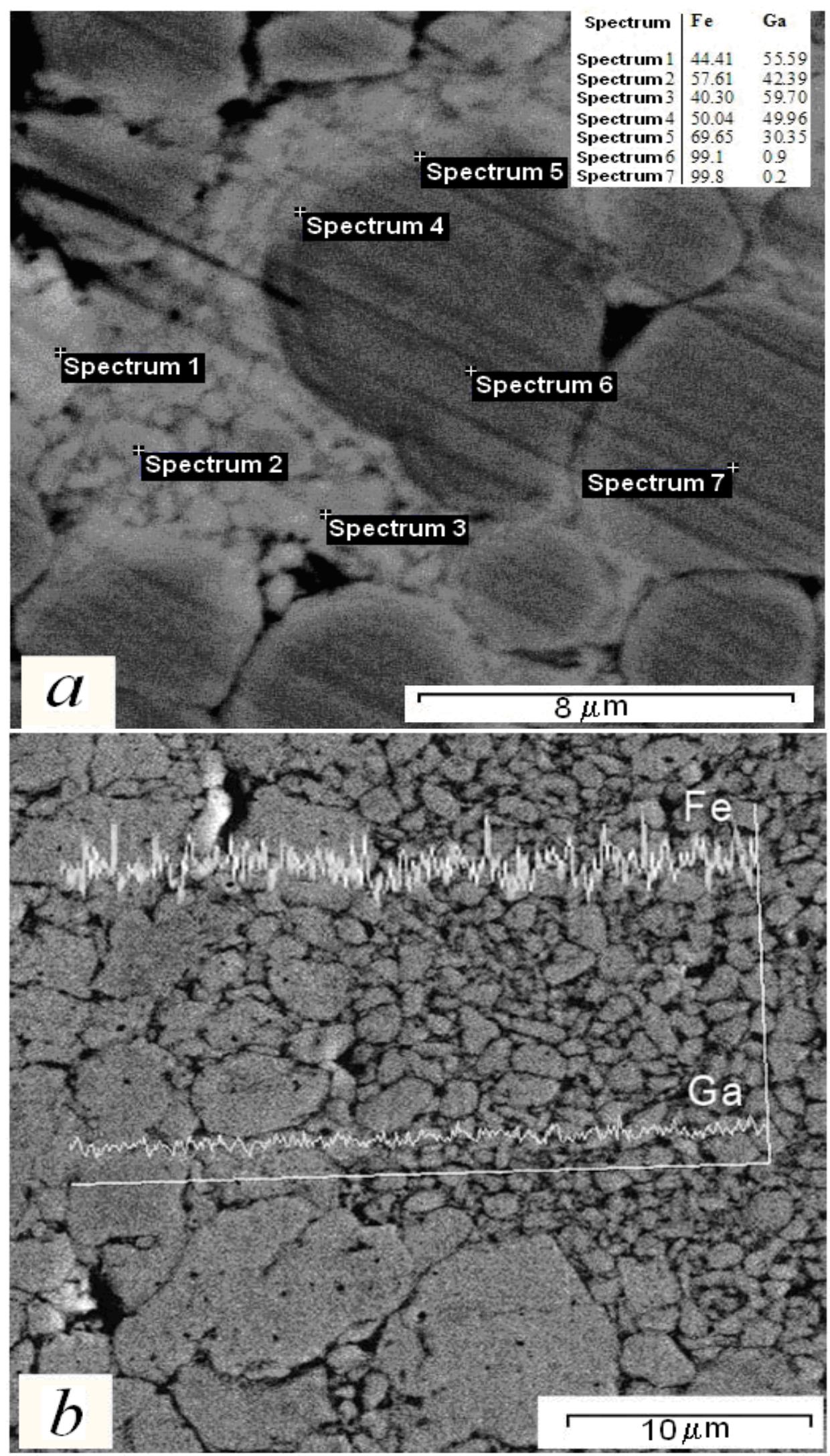

Fig. 3 SEM image of the microstructure of alloys based on mechanocomposites: (a) after MA for 12 min and (b) after MA for $150 \mathrm{~min}$. 
varies within the ranges $1-3 \mu \mathrm{m}$ and $8-13 \mu \mathrm{m}$. Small grains arranged as local regions. The areas characteristic of secondary recrystallization are observed: large grains surrounded by a large number of small grains. The grains have polygonal shape and possess developed internal substructure. As shown by the micro X-ray spectral analysis, the distribution of gallium and iron in coarse and fine grains is homogeneous (Fig. 3b). The presence of intra-grain porosity is characteristic of the alloys; an increase in surface porosity to $8 \%$ is observed, with the average pore size around $1.5 \mu \mathrm{m}$.

Microhardness of sintering materials obtained in the same regimes is substantially dependent on the structure and phase content of initial mechanically activated $\mathrm{Fe}+20 \% \mathrm{Ga}$ powders. Thus, microhardness of the alloy obtained from mechanocomposite activated mechanically for $2 \mathrm{~min}$ is $360 \mathrm{HV}_{200}$. Microhardness of the alloy based on mechanocomposite activated mechanically for $12 \mathrm{~min}$ increases up to $700 \mathrm{HV}_{200}$, while microhardness of the alloy based on the powders activated for $150 \mathrm{~min}$ reaches $780 \mathrm{HV}_{200}$. A substantial increase in the hardness may be due to the formation of harder phases and the formation of block nanocrystalline substructure.

\section{Conclusions}

It was established in structural studies of the alloys obtained by sintering the powdered mechanocomposites having the composition $\mathrm{Fe}+20 \%$ $\mathrm{Ga}$ at high pressure and temperature that the structural phase state of mechanocomposites is determined by the regimes of mechanical activation and affects the mechanisms of powder sintering and the microstructure of sintered materials.

Grained structure with rounded grains and interparticle pores is formed in the sintered composite activated mechanically for $2 \mathrm{~min}$; this shape is characteristic of liquid-phase sintering with the dissolution of the solid phase in the liquid phase.
Microhardness of the resulting material is $360 \mathrm{HV}_{200}$

An increase in precursor MA time to $12 \mathrm{~min}$ results in the formation of intermetallic compounds $\mathrm{Fe}_{3} \mathrm{Ga}_{4}$ and $\mathrm{Fe}_{6} \mathrm{Ga}_{5}$ during sintering; the microhardness of the resulting material increases by a factor of 2 .

Sintering of $\mathrm{Fe} / \mathrm{Fe}(\mathrm{Ga}) / \mathrm{Fe}_{3} \mathrm{Ga}$ mechanocomposites $\left(\mathrm{DO}_{3}+\mathrm{Ll}_{2}\right)$ has a solid-phase nature and proceeds without changes in phase composition. The alloys are characterized by grain size within the range 1-3 $\mu \mathrm{m}$ and $8-13 \mu \mathrm{m}$, and intragranular porosity. The distribution of iron and gallium elementsl in the material is homogeneous, microhardness is $780 \mathrm{HV}_{200}$.

Sintering of the mechanocomposite obtained after MA for $150 \mathrm{~min}$ leads to a decrease in the average crystallite size $<\mathrm{L}>$ to $5 \mathrm{~nm}$.

\section{Acknowledgments}

The work was supported by the Joint project of the SB RAS and the National Academy of Sciences of Belarus, No. 8

\section{References}

[1] Kellogg, R. A., Flatau, A., Clark, A.E., Wun-Fogle, M. and Lograsso, Th. 2003. "Quasi-Static Transduction Characterization of Galfenol." In Proceedings of IMECE'03, ASME International Mechanical Engineering Congress, 1-8.

[2] Khmelevska, T., Khmelevskyi, S. and Mohn, P. 2008. "Magnetism and Structural Ordering on a BCC Lattice for Highly Magnetostrictive Fe-Ga Alloys: A Coherent Potential Approximation Study." J. Appl. Phys. 103: 073911.

[3] Guruswamy, S., Srisukhumbowornchai, N., Clark, A. E., Restorff, J. B. and Wun-Fogle, M. 2000. "Strong, Ductile, and Low-Fild Magnetostrictive Alloys Based on Fe-Ga." Scripta Materialia 43: 239-44.

[4] Bush, A. A., Kamentsev, K. E., Meshcheryakov, V. F., Fetisov, Yu. K., Chashin, D. V. and Fetisov, L. Yu. 2009. "Low-Frequency Magnetoelectric Effect in a Galfenol-PZT Planar Composite Structure." Technical Physics. The Russian Journal of Applied physics 54: 1314-20.

[5] Lomovsky, O. I. (Ed.) 2010. "Mechanocomposites as Precursors for Materials with New Properties." Publishing House of SB RAS, Novosibirsk.

[6] Alymov, M. I. 2010. "Construction Powder Nanopaterials." Composites and nanosturctures 2: 5-11. 
[7] Miedema, A. R., Chatel, P. F. and Boer, F. R. 1980. "Cohesion in Alloys - Fundamental of a Semi-Empirical Model." Physica B 100: 1-28.

[8] A handbook: in 3 volumes. 1997. Mashinostroenie, Moscow.
[9] Grigorieva, T. F., Kiseleva, T. Yu., Kovaleva, S. A., Novakova, A. A., Tsybulya, S. V. and Barinova, A. P. et al. 2012. "Investigation of the Products of Iron and Gallium Interaction during Mechanical Activation." Fizika Metallov I Metallovedenie. 113: 607-14. 